\title{
WORK MOTIVATION OF LECTURERS IN NON-PUBLIC UNIVERSITIES: THE CASE OF HO CHI MINH CITY, VIETNAM
}

\author{
Ai Tran Huu \\ My Phạm Thi Chieu \\ My Phan Thi Tra
}

Van Hien University, Ho Chi Minh City, Vietnam

This study analyzes the factors affecting work motivation of non-public university lecturers in Ho Chi Minh City through confirmatory factor analysis and structural equation modeling based on the survey data of 253 university lecturers. The research results show 6 factors that positively affect the work motivation of lecturers: advancement opportunities (AO), organizational culture (OC), recognition of individual contribution (RIC), lecturer's qualifications (LQ),wages and other benefits (WB), working environment (WE). Two more factors have been found to be not statistically significant -- the characteristics of teaching and learning (CTL) and the class size (CS). Our conclusion is that schools should pay more attention to improving the working environment, by means of providing appropriate and

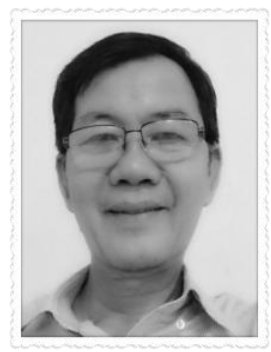

\section{Ai Tran Huu}

$\mathrm{PhD}$, lecturer of Faculty of Economics, Van Hien University, Ho Chi Minh City, Vietnam

Research interests - markets of agricultural products, SMEs functioning and government support, organic food markets, ecological economics, environmental issues of economic development and corporate social responsibility

Published more than 60 papers in International journals, member of editorial board of International journals

E-mail: aith@vhu.edu.vn

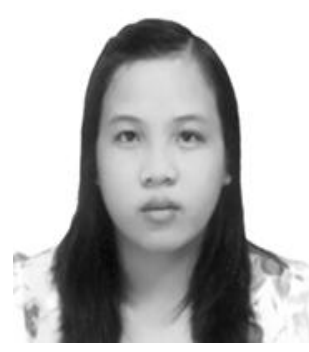

\section{My Phan Thi Tra}

MBA, Lecturer of Faculty of Economics, Van Hien University, Ho Chi Minh City, Vietnam

Research interests: SMEs functioning and government support, consumer behavior, innovative products markets and finances.

Published more than 20 papers in International journals.

E-mail: myptt@vhu.edu.vn

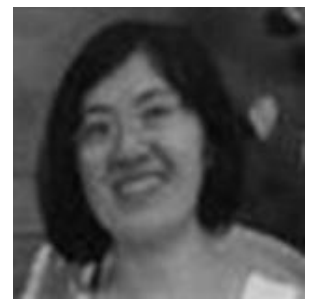

\section{My Pham Thi Chieu}

MBA, Lecturer of Faculty of Economics, Van Hien University, Ho Chi Minh City, Vietnam

Research interests: SMEs functioning and government support, consumer behavior, innovative products markets and finances.

Published more than 20 papers in International journals.

E-mail: myptc@vhu.edu.vn 
timely forms to assess and acknowledge the contributions of teachers to the school, thereby creating more motivation for them to contribute even more in the future.

Keywords: work motivation; non-public university; lecturers; survey; Vietnam

\section{Introduction}

In the context of the ongoing 4.0 revolution, there are many new opportunities and challenges arising for universities in general and non-public universities in particular. In order to survive and develop in the most sustainable way, non-public universities have to pay special attention to human-related factors. Non-public universities today are struggling with not only retaining universities lecturers but also with the overall development of policies to enhance work motivation and teaching aspirations among lecturers. In order to do this, nonpublic universities must first have a systematically constructed theoretical basis for full explanation of work motivation of the university lecturers and the factors affecting this motivation. Then, universities need to assess the actual situation with motivation and the impact of the related factors on motivation of university lecturers. On that basis, non-public schools will have both theoretical and practical grounds to develop the related policies with the key aim to enhance work motivation among university lecturers.

In the world literature on the subject matter, there are many different views on labor dynamics, including those belonging to Maier and Lauler (1973), Bedeian (1993), Kreitner (1995), Higgins (1994). Some of these and other studies refer to two groups of factors affecting motivation: the group of factors belonging to lecturers themselves and the second group of environmental factors. The researchers also showed how work motivation can be approached in two different ways. For example, there is the so-called content doctrine (Maslow, Alderfer, McClelland, Herzberg) which shows how to approach the needs of employees. And there is also the theory of process groups (Adams, Vroom, Skinner, Locke) which stems from the question of why each person shows different actions at work. Applying these theories, together or separately, some domestic and foreign studies have shown motivational factors in the course of their actual implementation at work.

However, many teachers are familiar with the one-way knowledge transfer method, the knowledge connection directed on the students with limited life experience, leading to passive students' acquisition of knowledge. In many such cases students will not be able to use the knowledge learned in their own life events. Meanwhile, innovative teaching today requires teaching staff implement teaching methods towards integrating, differentiating, promoting proactive and creative student capacities. Therefore, work motivation of trainers has become an important issue, as lecturers are assigned the responsibility to convey knowledge and skills to learners.

Mertler (1992) argued that lecturers are satisfied when they are in a good teaching environment, then teaching becomes more effective and can affect students' achievements. However, measuring the determinants and effects of working motivation of lecturers is complicated because these psychological processes cannot be directly observed and there are many organizational and conditional obstacles that can affect the goals achieved. Thus, motivation of teachers depends on effective management, especially at the school level. If the system and the structure are set up to manage and support faculty members who are not working well enough, teachers may lose their sense of professional responsibility and 


\section{WORK MOTIVATION OF LECTURERS IN}

commitment to their school. Management of teachers is the most important thing at the school level, whereas the importance of faculty work and their capacity in teaching are greatly influenced by the quality of internal and external monitoring.

Analyzing non-public universities in HCM city, we have found that in the motivating work of lecturers at non-public universities, there are certain limitations as follows:

- The remuneration policy is not appropriate for lecturers to be enthusiastic about their jobs, thus, their long-term work is not assured enough. Management regime also has a heavy centralized mechanism, the mechanism of human resource management is also quite heavy, with many administrative procedures involved. The incentive and remuneration mechanisms have not been given enough care. The motivational program has many shortcomings, moreover, there is a significant gap between the salary of old teachers and younger lecturers.

- Criteria for rewards are not exactly unclear, and this fact is causing various attitudes among lecturers; reward consideration process cannot be called fair as such;

- Policies on training and development of human resources have not been invested enough and not paid due attention. There is no welfare policy developed for teachers with difficult life circumstances. There is also lack of encouragement for the teachers who have already improved the level of service activities etc.

- Evaluation of work and all related changes are highly subjective and depend directly on the school owner.

\section{Literature review}

Working motivation is the desire and willingness of employees to strengthen their efforts towards the achievement of organizational goals; it provides impulse, consistency, and perseverance in the process of working (Stee \& Porter, 1983). In order to have the right motivation, first, there is a need, a desire to satisfy needs, they will motivate people to act. In other words, this need and this desire to satisfy certain expectations are the basis that motivates people to act. Motivational theories revolve around the question of human needs. To motivate employees, leaders first of all need to pay attention to their needs, see what needs they have and facilitate them to strive to satisfy their needs. There are many studies on work motivation of workers; many motivational theories have been presented to date.

Each theory has its own unique points, having different views on this issue, going into each aspect and exploiting different aspects of the influencing factors. This suggests that the issue of motivation in labor is a complex one, subject to many aspects, many factors such as Maslow's demand theory, Herzberg's two-factor theory, theory by J. Stacy Adams, the expectant theory of Victor Vroom etc. Each theory considers working motivation from different angles and different approaches.

In this study, the authors focus on: Maslow theory; Stacy Adams' doctrine of fairness; two engine elements by Frederic Herzberg; job characteristics theory of Hackman and Oldham. According to Bedeian (1993), motivation is an attempt to achieve a goal. Kleinginna (1981) stated that motivation is a push from within individuals to meet their unsatisfied needs. Motivation of teachers is an important issue, as they are assigned to communicate knowledge and skills to learners. In general, if teachers are satisfied, teaching is more effective and can affect students' achievement (Mertler, 1992). An enthusiastic lecturer usually has dedicated commitment to devote him/herself to work. That means they 
will prepare, teach and evaluate students' work on time and assume their responsibilities as always top priority (Aaronson, Lisa \& William, 2007).

Stemming from Lawler's motivation theories (1973), two elements theories of Hertzberg (1966) and other studies in the field of faculty work motivation, the general scale of work motivation is not a sufficient tool to fully evaluate the motivation of university lecturers. In this context (Orji Friday Oko, 2014) developed a teacher motivation scale to measure university lecturers' work motivation. These authors have chosen the model by Hertzberg (1966) and then developed it further.

Table 1. Components of the scale in the proposed model

(Source: made by co-authors)

\begin{tabular}{|l|l|}
\hline \multicolumn{1}{|c|}{ Measures of the components } & \multicolumn{1}{c|}{ Authors } \\
\hline Characteristics of teaching and learning & Hertzberg (1966) \\
\hline Class size & Orji Friday Oko (2014) \\
\hline Lecturer qualifications & Orji Friday Oko (2014) \\
\hline Recognition of individual contributions & Rose Nafula Situma (2015), Maslow (1943), \\
\hline Wages and other benefits & Orji Friday Oko (2014), Adam (1989) \\
\hline Working environment & Orji Friday Oko (2014), Rose Nafula Situma (2015) \\
\hline Advancement opportunities & Muhammad Imran Rasheed (2010), Hertzberg (1966) \\
\hline Culture of the organization & Lawler (1973), Hertzberg (1966) \\
\hline Working motivation & Muhammad Imran Rasheed (2010), Lawler (1973) \\
\hline
\end{tabular}

\section{Research hypotheses}

Characteristics of teaching and learning (CTL): Teaching and learning actively pay attention to the interest of learners as well as needs and benefits of the society. Under the guidance of teachers, students are proactively selecting the issues that interest them, for the subsequent self-study, research and presentation. Thanks to the sufficient attention of lecturers and the excitement of today's learning games that promote higher self-reliance in the first place, even the most restrained people start learning how to work independently, how to develop creative thinking, skills to organize own work and do presentations of own result. Therefore, the first hypothesis is suggested as follows:

$\mathrm{H} 1$ : Characteristics of teaching and learning have a positive impact on working motivation.

Lecturer qualifications (LQ): Currently, application of information technologies in teaching at schools is an indispensable requirement for lecturers, however, access to technology for faculty members has been quite an issue for a long time. Trainings on "information digging" and its further creative processing are still urgently required for many faculty members. This necessity assumes managers need to have specific and appropriate plans to carry out such trainings and thus improve technical qualifications of lecturers so that the latter meet the requirements of their own jobs. This motivates lecturers to strive to study and research and therefore improve their qualifications. Therefore, the second hypothesis is suggested as follows: 


\section{WORK MOTIVATION OF LECTURERS IN}

\section{H2: Lecturers' qualifications have a positive impact on working motivation.}

Class size (CS): According to the classical theory, classroom should not exceed 35 students. Practical classes should be no more than 18 students for normal occupations; and no more than 10 students for heavy, toxic and other dangerous studies and trades. These standards are according to the List issued by the Ministry of Labor, War Invalids and Social Affairs. Therefore, the third hypothesis is suggested as follows:

H3: Class size has a positive impact on working motivation.

Recognition of individual contributions (RIC): This category can be applicable for separate individuals or for evaluation of people in a university overall. People are normally stimulated when their behavior is judged correctly through compliments (when there are good results, of course) or punishments (when the results are unsatisfactory). So the 4th hypothesis is suggested as follows:

H4: Recognition of individual contributions has a positive impact on working motivation.

Wages and benefits (WB): Organizations cooperate with own workers using the system of income policies. This is the system which includes policies ensuring benefits for employees: policies on salaries, bonuses, on social insurance, policies on allowances and so on. From the perspective of human resource management in organizations, policies on salary, social insurance and allowances together form a group of factors that are capable to attract and maintain employees (through provision of necessary conditions). For the absolute majority of individuals, a reasonable salary policy and full coverage by the social insurance policy are solid motivators to take efforts and complete the assigned work.

On the other hand, there is a surprising finding by Herzberg that wages generally do not motivate employees, even though delayed pay can make people dissatisfied. This paradox is still not clear and definitely requires additional research. Most people go to work to earn money, but when we are engrossed in our work and enjoy it, we will not think about wages. However, wages become extremely important when employees feel they are being paid inadequately or when the company is late in paying wages. At the same time, cash rewards based on the results of a whole group often have great incentive effects. In this case, money is used as a work motivation tool. Therefore, the 5th hypothesis is suggested as follows:

H5: Wages and benefits have a positive impact on working motivation.

Working environment (WE): This category includes the elements of equipment, organization and workplace, hygiene, environmental factors and various other. Cooperation in labor also has a great impact on the ability to work, health status, work attitudes, and overall work efficiency. If teachers are allowed to work under good working conditions (adequate and modern teaching equipment, classrooms are arranged in a reasonable manner, the workload is well managed, safety and health protection of teachers are insured, there is a psychological atmosphere of comfort and trust among employees etc.), this will make teachers feel comfortable while working, and there will be sufficient conditions to promote creativity, reconsider lesson design and so on. Therefore, managers must regularly care about 
creating most favorable conditions for teachers so that they can work hard but also creatively. Therefore, the 6th hypothesis is suggested as follows:

H6: Working environment has a positive impact on working motivation.

Advancement opportunities (AO): Advancement in work is the development in the career ladder, showing the recognized need, is being affirmed. According to Frederick Herzberg's research, promotion is a factor of satisfaction, encouraging employees to work hard at work. In fact, a good lecturer often has a spirit of progress. They are always eager to seek opportunities to advance their career development because they think that they will not move backward. The advancement of employees has an important meaning and is always a matter of concern in improving motivation for employees at the units. However, this is a complicated and very difficult job, if used improperly can have disastrous effects. Therefore, the 7th hypothesis is suggested as follows:

H7: Advancement opportunities has a positive impact on working motivation.

Organizational culture (OC): Organizational culture is a system of common values and norms recognized by all employees in an organization, and their behavior both inside and outside their own organization. Organizational culture is expressed, for starters, through the logo as the core symbol of organization but most specifically - through the working style, relations between colleagues and between employees and managers. The atmosphere of active scientific activities will create a strong cultural environment when it comes to universities. Strong culture appeals to talents and promotes passion for scientific research. Therefore, to create motivation, it is necessary to build and maintain a strong culture in the heart of the people who are doing the science for their school. Therefore, the 8th hypothesis is suggested as follows:

H8: Organizational culture has a positive influence on working motivation.

\section{Research methodology}

According to Sentosa et al. (2012), the number of observations (the sample size) must be at least 4 to 5 times the number of variables in factor analysis. Thus, since the official data used in this study has been analyzed by means of a linear structure model, to achieve a reliable estimate for this method, the sample size was 48 variables x $4=192$ samples. According to our research topic we have applied the method of random stratified sampling. All information has been collected from the lecturers currently teaching at non-public universities in HCMC, Vietnam.

Quantitative measures have been thus applied to the data of 2 surveys - the official and the additional ones. After the review and consultations with the research team in the field of education, the main factors affecting motivation of faculty have been outlined. In our study the observed variables have been assessed using the Likert scale with 5 levels (in which $1=$ very dissatisfied, level $2=$ dissatisfied, level $3=$ temperate, level $4=$ satisfied and level $5=$ very satisfied); there were also 8 groups of potential scales (with the total of 48 observed variables), all affecting the work motivation of lecturers.

According to Hair et al. (2009), the minimum sample size is calculated by the formula $50+8 * \mathrm{~m}$ (where $\mathrm{m}$ is the number of independent variables). In this study, there are 8 independent variables, thus, the minimum sample size is $50+8 * 8=114$ observations. Thus, summing up the above two requirements, to achieve the research target we need the 


\section{WORK MOTIVATION OF LECTURERS IN}

minimum sample size for this study to be at at least 192 observations. Therefore, the authors conducted the survey by sending questionnaires to 312 lecturers, all of them currently working on the main campuses of the Ho Chi Minh City. The authors have divided the whole group into the groups according to the training industry characteristics. These were lecturers working at non-public schools of the economic sector, engineering and in social sciences. The final number of the returned questionnaires was 253 (which means the return rate is $83.77 \%)$.

Table 2. Statistics of the survey samples

(Source: by the authors)

\begin{tabular}{|c|c|c|c|c|c|c|c|}
\hline Faculty & Frequency & Percent & $\begin{array}{c}\text { Cumulative } \\
\text { Percent }\end{array}$ & Ages & Frequency & Percent & $\begin{array}{c}\text { Cumulative } \\
\text { Percent }\end{array}$ \\
\hline Tourism department & 53 & 20.95 & 20.95 & $>25-=<30$ & 58 & 22.92 & 22.92 \\
\hline Economics & 48 & 18.97 & 39.92 & $>30-=<40$ & 87 & 34.39 & 57.31 \\
\hline Humanities and Social Sciences & 54 & 21.34 & 61.26 & $>40-=<50$ & 54 & 21.34 & 78.66 \\
\hline Foreign language department & 53 & 20.95 & 82.21 & $>50-=<60$ & 32 & 12.65 & 91.30 \\
\hline Information Technology & 45 & 17.79 & 100.00 & $>60$ & 22 & 8.70 & 100.00 \\
\hline Total & 253 & 100 & & Total & 253 & 100.00 & \\
\hline Male & 135 & 53.36 & 53.36 & University level & 14 & 12 & 12 \\
\hline Female & 118 & 46.64 & 100 & Graduate degree & 103 & 88 & 100 \\
\hline Total & 253 & 100 & & Total & 253 & 100 & \\
\hline
\end{tabular}

\section{Results of the confirmatory factor analysis (CFA)}

CFA results show that all standardized estimates of the factor loadings are of high value. The conformity assessment criteria have the chi-squared value of 310.109 , with 260 degrees of freedom and the value of $\mathrm{p}=.018$. The squared value relative to the degrees of freedom CMIN / df is $1.193(<0.2)$. Other indicators have been: GFI $=0.845(>0.8)$, TLI = $0.951(>0.9), \mathrm{CFI}=0.961(>0.9)$ and RMSEA $=0.041(<0.08)$. Therefore, we can state that this model is suitable for the market data. This also allows us draw judgments on the unidirectionality of the observed variables. Regarding the convergent values, the standardized weights of all scales are $>0.5$ and statistically significant at $p<0.5$, so the scales achieve convergent values. 


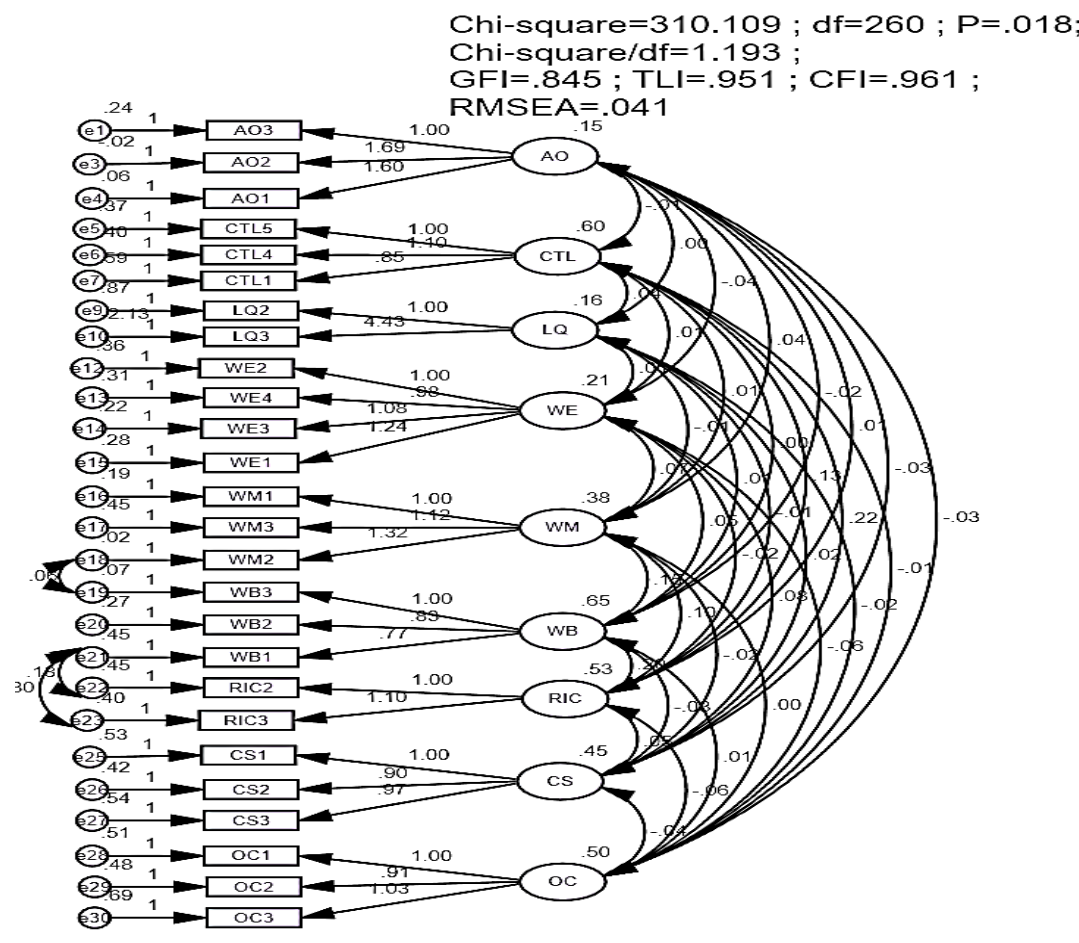

Figure 1. Results of the Confirmatory Factor Analysis CFA) (Source: Designed by the authors)

Table 3. Results of verification of the discriminatory value of CFA scale of the research model

(Source: Calculated by the authors)

\begin{tabular}{lcccc}
\multicolumn{1}{c}{ Relationship } & Estimates & Standard errors & Critical Ratios & P-value \\
Organizational culture & 0.424 & 0.127 & 3.334 & $* * *$ \\
Advancement opportunities & 0.434 & 0.057 & 7.619 & $* * *$ \\
Working environment & 0.504 & 0.146 & 3.465 & $* * *$ \\
Wages and benefits & 0.437 & 0.057 & 7.669 & $* * *$ \\
Characteristics of teaching and learning & 0.336 & 0.082 & 4.071 & $* * *$ \\
Lecturer qualifications & 0.425 & 0.091 & 4.679 & $* * *$ \\
Recognition of individual contributions & 0.470 & 0.126 & 3.737 & $* * *$ \\
Class size & 0.472 & 0.149 & 3.173 & 0.002 \\
Working Motivation & 0.189 & 0.214 & 0.880 & 0.039
\end{tabular}




\section{WORK MOTIVATION OF LECTURERS IN}

\section{The relational structure in the final model (SEM)}

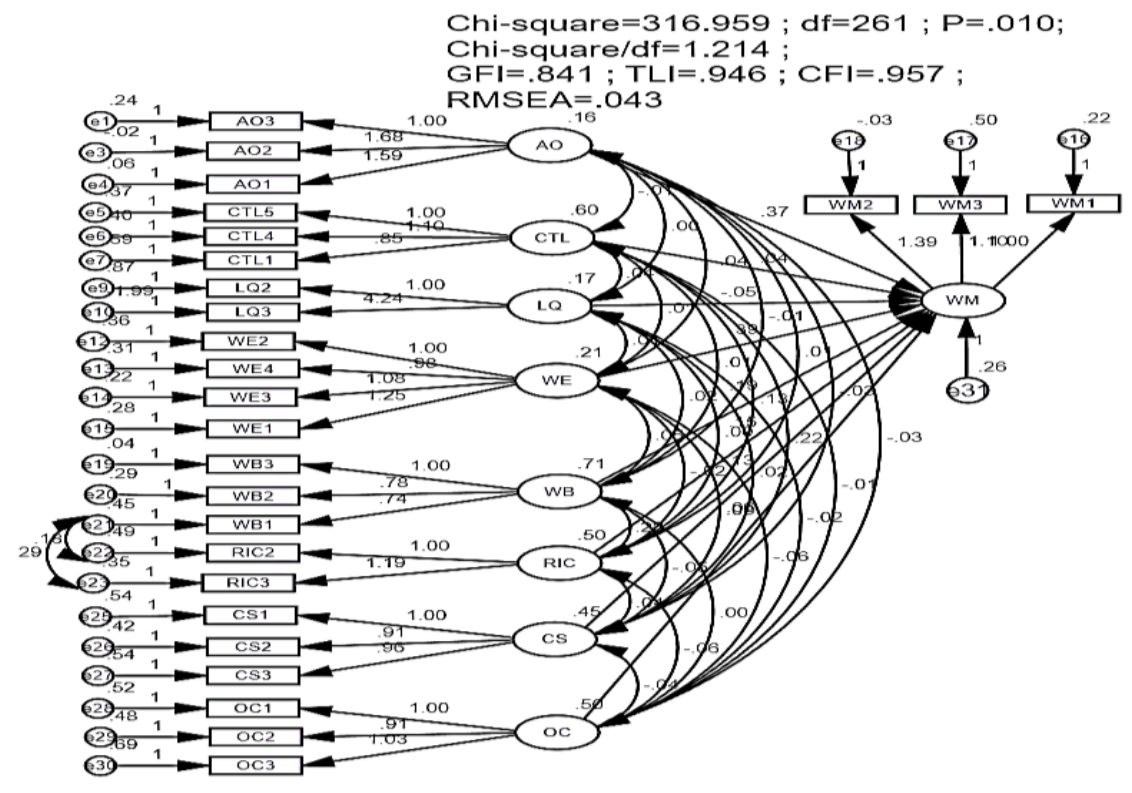

Figure 2. Results of our modeling (standardized)

(Source: calculated and designed by the authors)

Model structure (SEM) has been implemented to understand the relationship between the factors affecting work motivation of the faculty. The results show that the model with the following calibrated values together with the squared statistical expenditure is 316,959 , with 261 degrees of freedom $(\mathrm{P}=0,010)$, the relative generality of freedom is equal to $\mathrm{Cmin} / \mathrm{df}$ $1,214(<2)$. Other indicators are: $\mathrm{GFI}=0.841(>0.8), \mathrm{TLI}=0.946(>0.9), \mathrm{CFI}=0.957(>0.9)$ and RMSEA $=0.043(<0.08)$. Therefore, this model has achieved compatibility with the collected data.

Table 3. Results of testing the causal relationship between the concepts in theoretical models (Source: calculated by the authors)

$\begin{array}{lclcccc} & \text { Relationship } & \text { Estimates } & \begin{array}{c}\text { Standard } \\ \text { errors }\end{array} & \begin{array}{c}\text { Critical } \\ \text { Ratios }\end{array} & \text { P-value } \\ \text { AO } & \text {--> } & \text { WE } & -0.088 & 0.041 & -2.136 & 0.033 \\ \text { AO } & <--> & \text { WM } & 0.081 & 0.039 & 2.087 & 0.037 \\ \text { WE } & <--> & \text { WM } & 0.081 & 0.040 & 2.015 & 0.044 \\ \text { WE } & <--> & \text { CS } & 0.115 & 0.055 & 2.103 & 0.035 \\ \text { WB } & <--> & \text { RIC } & 0.170 & 0.061 & 2.772 & 0.006 \\ \text { WB } & <--> & \text { WM } & 0.146 & 0.045 & 3.271 & 0.001 \\ \text { CTL } & <--> & \text { CS } & 0.238 & 0.073 & 3.254 & 0.001 \\ \text { LQ } & <--> & \text { CS } & 0.122 & 0.062 & 1.953 & 0.050 \\ \text { RIC } & <--> & \text { WM } & 0.162 & 0.057 & 2.851 & 0.004\end{array}$


The estimation results of the weights in Tab. 4 demonstrate that only 6 components (Advancement Opportunities, Working Environment, Welfare and benefits, Lecturer qualifications, Recognition of individual contributions and Organizational culture) have statistical significance $(\mathrm{p}<0.05)$, while such components as Characteristics of teaching and learning $(\mathrm{p}=0.933)$ and Class size $(\mathrm{p}=0.410)$ are under $\mathrm{P}>0.05$, so they are not statistically significant. This indirectly proves that the University has not paid adequate attention to these factors, which may be due to the management viewpoint of the executive board.

Table 4. Results of testing the causal relationship in the hypotheses

(Source: Calculated by the authors)

$\begin{array}{llllcccc} & \text { Content } & & \text { Estimate } & \text { S.E. } & \text { C.R. } & \text { P } & \text { Label } \\ \text { WM } & <-- & \text { AO } & 0.213 & 0.081 & 2.627 & 0.009 & \text { Yes } \\ \text { WM } & <-- & \text { WE } & 0.312 & 0.116 & 2.698 & 0.007 & \text { Yes } \\ \text { WM } & <--- & \text { WB } & 0.238 & 0.094 & 2.536 & 0.011 & \text { Yes } \\ \text { WM } & <--- & \text { CTL } & -0.011 & 0.125 & -0.084 & 0.933 & \text { No } \\ \text { WM } & <--- & \text { LQ } & 0.070 & 0.070 & 0.995 & 0.020 & \text { Yes } \\ \text { WM } & <-- & \text { RIC } & 0.210 & 0.099 & 2.116 & 0.034 & \text { Yes } \\ \text { WM } & <--- & \text { OC } & 0.065 & 0.085 & 0.758 & 0.048 & \text { Yes } \\ \text { WM } & <--- & \text { CS } & -0.111 & 0.135 & -0.823 & 0.410 & \text { No }\end{array}$

\section{Checking the reliability of estimates with bootstrap}

The estimated results from 1000 averaged samples together with the deviations are shown in Table 5, where CR absolute value is less than 2, thus, it can be said that the deviation is very small; while also not statistically significant at the $95 \%$ confidence level. Therefore, we can conclude that the model estimates can be reliable. There are 8 relationships that are proved to be theoretically valid.

Table 5. Results estimated by means of bootstrap with $n=1000$ in the theoretical model (Source: Calculated by the authors)

\begin{tabular}{|c|c|c|c|c|c|c|c|c|}
\hline \multicolumn{3}{|c|}{ Parameter } & $\mathrm{SE}$ & SE-SE & Mean & Bias & SE-Bias & CR \\
\hline WM & $<--$ & $\mathrm{AO}$ & 0.200 & 0.004 & 0.357 & -0.012 & 0.006 & -0.50 \\
\hline WM & $<---$ & CTL & $0.2-3$ & 0.005 & 0.059 & 0.022 & 0.007 & 0.32 \\
\hline WM & $<---$ & LQ & 0.115 & 0.003 & -0.107 & -0.056 & 0.004 & -0.07 \\
\hline WM & $<---$ & WE & 0.592 & 0.013 & 0.562 & 0.172 & 0.019 & 0.11 \\
\hline WM & $<---$ & WB & 0.096 & 0.002 & 0.170 & -0.021 & 0.003 & -0.1 \\
\hline WM & $<---$ & RIC & 0.127 & 0.003 & 0.145 & -0.010 & 0.004 & -0.4 \\
\hline WM & $<---$ & $\mathrm{CS}$ & 0.329 & 0.007 & -0.169 & -0.036 & 0.010 & -0. \\
\hline WM & $<---$ & $\mathrm{OC}$ & 0.157 & 0.004 & 0.081 & 0.017 & 0.005 & \\
\hline
\end{tabular}

\section{Discussion of the results}

The research results show that there are 6 factors related to work motivation of lecturers of the non-public universities, both having positive and significant impacts at the 


\section{WORK MOTIVATION OF LECTURERS IN}

inspected level (95\%, M<0.05). More specifically: (1) Working environment (WE) with $\beta=$ $0.312(\mathrm{p}=0.007<0.05)$ has the strongest influence, showing that environmental conditions must, first of all, create comfortable conditions for mental activities and knowledge creation and thus help focusing on thinking, apart from labor conditions convenient for scientific research; (2)Wages and benefits (WB) with $\beta=0.238(\mathrm{p}=011<0.05)$ have the second strongest influence, thus indicating that lecturers are not really satisfied with the current salary and bonus regime. For some individuals, a reasonable salary policy and a full social insurance policy are motivators for their efforts to complete the assigned work. This needs to be considered more carefully.

The question is whether this is the general situation of universities across the country or is it the case of non-public universities only? (3) Advancement opportunities (AO) got $\beta=$ $0.213(\mathrm{p}=0.009<0.05)$. The third strongest effect shows that this is also a factor promoting the development of faculty capacities.

According to Frederick Herzberg's research, promotion is a factor of satisfaction, encouraging employees to work harder. They become more eager to seek new opportunities to advance their career development. (4) Recognition of individual contributions (RIC) has the fourth strongest effect, with $\beta=0.210(\mathrm{p}=0.034<0.05)$. This result indicates there should be clearer and publicly developed evaluation criteria for staff. Lecturers' evaluations should be conducted periodically to analyze and assess the contributions of individuals in school. (5) Lecturer qualification (LQ) got the result $\beta=0.070(p=0.020<0.05)$.

This shows that within the non-public university environment, development of qualifications are directly related to professional capacities. Therefore, creating favorable conditions policies for lecturers and other scientists will essentially improve their professional qualifications in terms of both teaching and research activities. (6) Organizational culture $(\mathrm{OC})$ with $\beta=0.065(\mathrm{p}=0.048<0.05)$ significantly affects teaching motivation of lecturers. In this study, the groups of organizational cultural factors have been established as follows: colleagues who are willing to help in work, competition among colleagues, colleagues who are reliable, colleagues who are friendly, other social effects on teaching and other work results.

There are also two factors that are not statistically significant because their values are $\mathrm{P}$ $>0.05$. Namely: (1) Characteristics of teaching and learning (CTL) with $\beta=-0.011(\mathrm{p}=$ $0.933>0.05$ ), showing that teaching and learning are seen as scientific and artistic work that requires mostly lecturers' creativity in the teaching process. In order to do well, lecturers must perform well in 3 main aspects -- preparation before classes, the period in class and after class. Without proper work motivation, none of stages would be successfully performed. 2) Class size (CS) got $\beta=-0.111(\mathrm{p}=0.410>0.05)$. This shows that teaching in large classes is a difficult job. Thus, teaching should be reorganized more logically, thus bringing positive learning experiences instead of just relying on the strength of group in learning activities. Teaching in large classes could also be effective; however, radical reorganization of teaching processes should be carried out then.

\section{Conclusions and recommendations}

The system of non-public universities has made positive contributions to Vietnam's higher education, however, it is still facing many shortcomings. Improving policies that are still inadequate is one of the solutions to help non-public universities increasingly affirm 
their role and position, but at the same time, schools also have to make efforts to improve themselves. Low quality of trainings and lack of proper motivation for teachers are only two in a range of weaknesses of the schools following this model.

Motivating work is an extremely important factor in managing work performance. In fact, this factor plays the key role in managing performance and is something that managers must always care about. The schools can actually train lecturers to overcome shortcomings and improve performance, but the instructors will not focus on training if they do not want to motivate themselves. Managers can also spend a lot of time evaluating lecturers' annual performance and discussing it, but then precious time will be wasted if the faculty has no incentive to develop further, after such a discussion. The principles of effective work motivation have been around for a long time. At any stage, leaders and managers should be aware of the importance of motivating.

For non-public universities, it is also very important to create motivation for lecturers as this is a decisive factor for the existence and development of the university as such. The success or failure of a school depends on how well this school is using the available tools to stimulate teachers and to maximize their ability to improve labor productivity, promote training activities effectively.

This is integral part of sustainable development of any university.

\section{References:}

Aaronson, D, Lisa, B. \& William, S. (2007). Teachers and Student Achievement in the Chicago Public High Schools, Journal of Labor Economics, 25: 95-135.

Adams, J. S. (1965). Inequity in social exchange. In L. Berkowitz (ed.), Advances in experimental social psychology. New York: Academic Press.

Alderfer, C. (1969). An empirical test of a new theory of human needs. Organizational Behavior and Human Performance, 4, 142-175.

Bedeian, A.G. (1993). Management (3rd edition). New York: Press Dryden.

Hair, J. F., Black, W. C., Babin, B. J., \& Anderson, R. E. (2009). Multivariate data analysis. Upper Saddle River, NJ: Prentice Hall.

Herzberg, F. (1966). Work and the nature of man. Cleveland: World Publishing Company.

Higgins, J. M. (1994). The management challenge. New York: Macmillan.

Kleinginna, P. \& Kleinginna, A. (1981). A categorized list of motivation definitions, with a suggestion for a consensual definition. Motivation and Emotion, 5,3: 263-291.

Kreitner, R. (1995). Management. Boston: Houghton Mifflin Company.

Lawler, E. E. (1973). Employee reactions to job characteristics. Journal of Applied Psychology, 55, 259-286.

Maslow, A. (1954). Motivation and personality, New York: McGraw Hill.

Mertler H. (1992). Value make the Company. Harvard Business Review.

Orji Friday Oko (2014). Impact of Teacher Motivation on Academic Performance of Students. Paper presented at the National Association of Mathematics Students Conference/Seminar.

Sentosa, I. et al. (2012). A Structural Equation Modeling of Internet Banking Usage in Malaysia. Journal of Arts, Science and Commerce, 3(1): 75-86.

Situma, R. (2015). Motivational factors affecting employees' performance in public secondary schools in Bungoma North Subcountry, Kenya. International Academic Journal of Human Resource and Business Administration, 1,5: 140-161.

Skinner, B. F. (1953). Science and Human Behavior. New York: Free Press.

Stee, R.M \& Porter, L.W (1983). Motivation: New directions for theory and research. Academy of Management Review, 17(1): 80-88. 


\section{WORK MOTIVATION OF LECTURERS IN}

Vroom, V. H. (1964). Work and motivation. New York: Wiley.

Paper submitted

Paper accepted for publishing

Paper published online
21 March 2019

25 May 2019

08 August 2019 